\title{
FLIPI Score 2, Intermediate Risk
}

National Cancer Institute

\section{Source}

National Cancer Institute. FLIPI Score 2, Intermediate Risk. NCI Thesaurus. Code C136967.

A score indicating that a patient has 2 risk factors associated with follicular lymphoma and is considered in the intermediate risk group. 